\title{
Perioperative care of patients undergoing non- elective laparatomy in a district general hospital
}

\author{
K Megaw*, J Greer, A Ferguson \\ From ESICM LIVES 2015 \\ Berlin, Germany. 3-7 October 2015
}

\section{Intr}

The Emergency Laparotomy Network have highlighted the significant morbidity and mortality associated with emergency abdominal surgery [1]. Poor standards of care have been identified by the National Confidential Enquiry into Patient Outcome and Death.

\section{Objectives}

Conduct a prospective audit of patients undergoing non-elective laparotomy in a district general hospital including time of day of surgery, seniority of personnel, post-operative disposition and post-operative complications.

\section{Methods}

Patients $\geq 50$ years undergoing non-elective laparotomy were included. Preoperative and intraoperative data were collected via standard proforma completed by attending anaesthetist. Post operatively, data were collected via standard proforma daily for 7 days.

\section{Results}

Data were collected for 43 patients ( 24 female), $65.1 \%$ were aged $60-79$ years and $62.3 \%$ were ASA 3. Preoperatively $16.3 \%$ received level 2 or 3 care. Prior to non-elective laparotomy $23.3 \%$ of patients had previous abdominal surgery within the preceding 11 days.

Seventy-three percent of surgeries were conducted from 08:00 to 17:59 (5\% from 00:00 to 07:59). Consultant surgeon and consultant anaesthetist were present intraoperatively in $80 \%$ and $72.5 \%$ of cases respectively and in $55 \%$ of cases were present together.

Immediate post-operative care was as follows: $46.5 \%$ post anaesthetic care unit (PACU), 11.6\% level 2 (non-PACU) and $41.9 \%$ level 3 care. From PACU, a

Craigavon Area Hospital, Anaesthetics and Critical Care, Portadown, United Kingdom

(c) 2015 Megaw et al.; This is an Open Access article distributed under the terms of the Creative Commons Attribution License (http:// creativecommons.org/licenses/by/4.0), which permits unrestricted use, distribution, and reproduction in any medium, provided the original work is properly cited. further $15 \%$ were transferred to higher level care at 6 hours. Mean length of stay in critical care 3.36 days (range 0.5 - 15.5 days) and in hospital 24 days (range 3 65 days).

The overall incidence of perioperative AKI between day 4 preoperatively and day 7 postoperatively according to AKIN classification and/or serum NGAL was $67.4 \%$. AKIN 3 was reached in $11.6 \%$ of patients and $7.0 \%$ received haemodiafiltration. AKI was unresolved at day 7 in $11.6 \%$.

Post-operative proforma were completed daily for $\geq 4$ days in 37 patients. Within the first 4-7 post-operative days, 14 patients required TPN, 4 patients had an episode of atrial fibrillation, 3 developed pneumonia, 3 congestive cardiac failure and 3 required a further laparotomy. Three patients were dead at 30 days.

\section{Conclusions}

The majority of operations occurred during the day and by senior staff however combined presence of consultant surgeon and anaesthetist could be improved. Utilisation of critical care resources was significant with $>68 \%$ of patients receiving level 2 or 3 care. The long hospital stay may be accounted for by the wide range of early post-operative complications and the high rate of repeat surgery. Limitations of the audit include lack of information on timeliness of surgery and on perioperative physiological disturbance.

Published: 1 October 2015

\section{Reference}

1. Saunders DI, Murray D, Pichel AC, Varley S, Peden CJ: Variations in mortality after emergency laparotomy: the first report of the UK Emergency Laparotomy Network. Br J Anaesth 2012, 109:368-375.

\section{doi:10.1186/2197-425X-3-S1-A234}

Cite this article as: Megaw et al:: Perioperative care of patients undergoing non-elective laparatomy in a district general hospital. Intensive Care Medicine Experimental 2015 3(Suppl 1):A234. 